\title{
Experienced and Well Structured Motivated Qualificated Decision Team by Patented Principles Utility Model S_T_A_R_S, 21532 CZ, 2010
}

\author{
Antonín Cuc* \\ The International Expert in Occupational Health and Safety, Europe \\ *Corresponding author: Antonín Cuc, The International Expert in Occupational Health and Safety, Na Mícánkách 435/1,10100 Prague 10, Czech \\ Republic, Europe
}

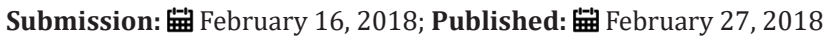

\section{Editorial}

The problem of proper collective decision making in a team that uses multidisciplinary scientific approaches should be based on the reasonable professional and well motivated staffing of the entire team, but they must go through a common initial "run-in" to make clear what decisive phenomena they must be able to recognize to evaluate and how to learn.

from the individual evaluations of the individual team members to come to the joint partial conclusions and to the final interpreting statistic representative conclusions, estimates of statistic parameters with statistic accuracy and statistic defined reliabilities - on the individual monitored phenomena, on the critical illegal situations of the patient Health care, the individual statistical units evaluated ... ie when checking the correct processing in diagnosis, checking the correct processing in choice the right individual treatment by the modern medical knowledges interdisciplinary of Encyklopedic Literature, assessing the illegal consequences of medical errors in diagnosis and in the choice of false individual treatment, evaluating the consequences of fatal unlawful medical errors by the decisions making on the Providers Health care and medical staff by the Health care for patient, the probable development of his/ her status of Health, the growth of fatal patient risks in next time and a biostatic probable enumerable effects on the likely median estimate of shortening the rest of the patient's life for a significant number of years to legal financial satisfactions including the Life assurance for worse mental and Physical Health status, Loss of Patient Lives. We should to understand to the casual history of afew individual Patient tragic growing the fatum to begin with next clever usage the Statistic method to detect similar medical mistakes EX POST, later so as for prevency to repeat medical mistakes EX ANTE.

In Orthopady CZ, you never could take Members in Decision Research Team CZ, because all Orthopadic Patients CZ there are living OR there are heavy injuring OR there are dying only unconditionally „LEGE ARTIS CZ“, by the constant false meaning of all Providers Health care CZ and medical staff CZ, by the constant false meaning all Knowing Medical Insitutes CZ, by the constant false meaning of Criminal Departments of Police CZ, by the constant false meaning of the all Justice CZ, by the meaning of the Heads of all Penalty Offices CZ - The Patient could be a silent Victim CZ only, without the Human Rights for Life and jusfied trueth verified Criminal evidences by the justified Court trials.

We are living live in the legal State of Czech Republic, where all unnecessarily mutilated or dying orthopedic patients of CZ have no real civil human rights to use forensic technical evidences by Court trials CZ - that they have been silent needless Victims CZ of The Mass repeated illegal fatal medical procedures in orthopadic Diagnostics or Treatments - for example contrary Technician Requirements of implanting Laws EU/CZ for guarancy the legal usage Medical Implants with "CE“ marking by the Technician Requirements of the Directive 93/42/EEC Medical Devices in common Market EU/CZ since April 1, 2004.

Since there are never seen any fatal official medical errors in Czech Orthopedics CZ, it is not real possible or desirable to detect or efficiency to prevent such massive medical orthopadic errors in medical orthopadic workflow, namely we don't solve tragic Fatums of Patient CZ in the Czech Republic, we don't caunt the yearly needless Patient Victims CZ. We are taking the false definition „LEGE ARTIS CZ“ regardless It has covered namely in Mass frequent repeated trivial technical medical fatal errors in Mass Medical processing CZ.

The needless Loss of Orthopedic Patient Life CZ has NONE of financial evaluating. Providers Health care CZ and medical staff are aboslute Scot - free for ever - in the secret continual civic war the Physicians CZ contrary Patients CZ with Mass yearly repeated similar Mass Medical errors in the standard medical orthopadic processing. In this my explanatory Article, I am deciding solitaire scientist - ONE MAN CZ ONLY - because the scientic Truth is interesting for US Medicine only, never for CZ Medicine.

Namely I am explaining the next Explanatory Orthopadic Case about false Diagnostics and with false choice the Treatments 
Necroses of femoral Head both my legs - as an pensioneer The State investigator of mortal occupational cases of Ministry for Labour and Social Affairs Czech Republic, so as a needless crippled too and just dying orthopadic Patient LEGE ARTIS CZ too - after to late diagnostics Necroses of Femoral Head with the false choice 3 needless folowing Treatments of illegal Orthopadic surgeries THA when there were recommended advanced more carefully and safety recommended NON-surgical treatments in time - by the World Encyclopedic Orthopadic Literature.

I have unofficial studied the contextual sufficient details of Human Orthopady in Necrosis of Femoral Head, Traumatology functional colapsing of human joints, principles of non-surgical treatments of Necroses femoral Head, The recommended classic arthroplasitc light Surgeries to reapair Human joints, comparing preferences Method Magnetic resonance and limitis in RTG imaging in Diagnostics of necrosis in Hip joints, Clinic mandatory Planning of standard individual Implanting Total Hip Arthroplasty, usual patient risks of Full Anesthesy, Neurologic transplantation and right timing of neurosurgical reconstruction the Nervus Ischiadici by full plegia in Traumatology cases, the typical complications Surgeries by Patient over Age 65+ by THA, Infects dangerous in Surgery Halls, Infect risks in postoperational orthopadic implanting, Typical dangerous Hemorragic preliminary Infects of Orthopadic Patients, typical preoperational and postoperational risks and Health complication by set THA with noncemented principles the Hip Artifitial joints, rational postoperational transfusions of Blood, prescriptions of Medicaments with risk of chemical mutual interactions, Posttraumatic Shocks on surgeon Halls, typical fatal mistakes of interpretation in Geometry 3D in Orthopadic Radiology by THA, Biomechanics and Designing functional sets THA by Producer Tests, Biostatistics analyses THA patient by returning locomotion abilities with modelling optimal possibilities by computer support of modelling, harmonised Laws EU/CZ in fields the Occupational Health and Safety, harmonised European Standards for the paralelly usage of rules the Directive Machinary, Directive 93/42/EEC Medical Devices - Research, Development, finished Testing new product sets THA, Regulation the Usage and State surveillance of usage Orthopadic Implants THA in common Market EU by Providers Health care, functional colapsing Implants, repairing. Rehabilitation support, Physiatric supporting praxes for postoperational locomotion abilites of Patient after THA, Statistic Growing Risks of repeated proximal fatal breacking of Femoral bones after repeated THA surgeries by happend fallen. The Duration of safety product lives in sets THA in long being safety patient usage for probable more as 20 years, Carcionomic risks by metalic and micro invasive PVC materials surfaces in frontiers the components of the Artifitial joints with surface of cavities of femoral bones, plevis hip sockets, destructions of the functional Technician Quality of mechanical Anchoring of centric placements of components THA in hip bones, Catastrophic preoperational situations „Ad hoc“ on the Surgeon Halls by implanting THA. Yes, I am just simulating personály in this Article - the perfect educated, structured and working decision making Team of experts for usage orthopadic sampling in Criminal analyses in the primary Dimense: The Statistic Unique entity-with explanation the decision making by my Method S_T_A_R_S, by The Utility model 21532 CZ 2010.

\section{Your subsequent submission with Crimson Publishers will attain the below benefits}

- High-level peer review and editorial services

- Freely accessible online immediately upon publication

- Authors retain the copyright to their work

- Licensing it under a Creative Commons license

- Visibility through different online platforms

- Global attainment for your research

- Article availability in different formats (Pdf, E-pub, Full Text)

- Endless customer service

- Reasonable Membership services

- Reprints availability upon request

- One step article tracking system 